and Morrison and Hill (1967), for example, have reported that for animals reared in isolation, the presence of other animals had little or no effect upon fear-reduction. On the other hand, for animals reared socially, the presence of other animals resulted in a reduction of fear-conditioned behaviors. This could be the case in the present experiment since all Ss were normally reared in groups.

\section{REFERENCES}

Angermeier, W. F., Philhour, P., \& Higgins, J. Early experience and social grouping in fear extinction of rats. Psychological Reports, 1965, 16, 1005-1010.

Baum, M. Extinction of an avoidance response motivated by intense fear: Social facilitation of the action response prevention (flooding) in rats. Behaviour Research \& Therapy, $1969,7,57-62$.
Davitz, J. R., \& Mason, D. J. Socially facilitated reduction of a fear response in rats. Journal of Comparative \& Physiological Psychology, 1955, 48, 149-151.

Hake, D. F., \& Laws, D. R. Social facilitation of responses during a stimulus paired with electric shock. Journal of the Experimental A naly sis of Behavior, 1967, 10, 387-392.

Korman, M., \& Loeb, J. Effects of the presence of another animal during acquisition and extinction upon the strength of a fear response. Journal of Comparative \& Physiological Psychology, 1961, 54, 158-161.

Latané, B., \& Glass, D. C. Social and non-social attraction in rats. Journal of Personality \& Social Psychology, 1968, 9, 142-146. Marina, J. F. Extinction of a conditioned avoidance response as a function of socially facilitated reduction of fear in rats. Unpublished thesis, University of Puerto Rico, 1972.

Masserman, J. H. Behavior and neurosis. Chicago: University of Chicago Press, 1943.

Morrison, B. J., \& Hill, W. F. Socially facilitated reduction of the fear response in rats raised in groups or in isolation. Journal of Comparative \& Phy siological Psychology, 1967, 63, 71-76.

(Received for publication December 5, 1973.)

\title{
Cross-modal matching by retarded and normal readers*
}

\author{
BILL JONES $\dagger$ \\ University of Waterloo, Waterloo, Ontario N2L 361, Canada
}

\begin{abstract}
Birch and Belmont (1964) claimed from a study of auditory-visual matching that retarded readers have a deficiency in auditory-visual integration. However, the present experiment indicates that when auditory-visual matching is compared with the relevant intramodal and visual-auditory matching tasks, retarded readers make fewer correct responses compared to normal readers only when an auditory pattern is the initial stimulus. A second experiment confirmed that retarded readers compared to normal readers were unable to hold an auditory pattern in short-term store, though there was no difference between the groups in the retention of a visual pattern.
\end{abstract}

Intuitively reading skills depend upon an integration of visual and auditory information. The person learning to read is shown a printed word (or perhaps the word and corresponding picture), a syllable, or even a letter, and taught the associated sound. Birch and Belmont (1964) found that retarded readers (dyslexics) were significantly inferior to normal readers, matched for age and IQ in auditory-visual (AV) matching, and they argued that retarded reading reflects a breakdown in AV integration. However, as Bryant (1968) has pointed out, errors in cross-modal matching (CMM) may be due to

*This paper is sponsored by M. P. Bryden, who takes full editorial responsibility for its contents. Thanks are extended to C. Cochrane for providing me with facilities to work with retarded readers.

+Present address: Department of Psychology, University of Waterloo, Waterloo, Ontario, Canada. failures of processing in one or both of the modalities involved instead of, or in addition to, failures of intersensory integration. Since Birch and Belmont (1964) included neither the relevant intramodal matching (IMM) tasks nor visual-auditory (VA) matching in their comparisons, their confident conclusion is unwarranted.

Further, as Rubinstein and Gruenberg (1971) point out, it is difficult to interpret even errors in AV matching using the Birch and Belmont procedure (an auditory pattern is tapped out; the $S$ has to select the correct visual match from a number of Morse-code-like visual patterns) since it may confound errors of temporal (auditory) to spatial (visual) transfer with CMM errors. The same criticism can be made of the work of Muehl and Kremenak (1966), even though they included IMM controls. There is evidence (Blank \& Bridger, 1966; 
Table 1

Mean Correct Responses (Out of 30) and Standard Deviations for Within- and Cross-Modal Matching

\begin{tabular}{|c|c|c|c|c|c|c|c|c|}
\hline \multirow{3}{*}{$\begin{array}{l}\text { Reading } \\
\text { Ability }\end{array}$} & \multicolumn{8}{|c|}{ Modal Condition } \\
\hline & \multicolumn{2}{|c|}{ VV } & \multicolumn{2}{|c|}{$\mathrm{AA}$} & \multicolumn{2}{|c|}{ VA } & \multicolumn{2}{|c|}{$\mathrm{AV}$} \\
\hline & Mean & SD & Mean & SD & Mean & SD & Mean & SD \\
\hline Normal & 25.5 & 1.87 & 26.2 & 1.17 & 26.7 & 1.17 & 26.7 & 1.86 \\
\hline Retarded & 27.0 & 1.55 & 21.3 & 1.63 & 27.5 & 2.07 & 20.0 & 2.37 \\
\hline
\end{tabular}

Blank, Weider, \& Bridger, 1968) that IMM in retarded readers is easier when patterns are spatially rather than temporally extended, and Goodnow (1971) has shown that the major change with age in matching visual to auditory patterns lies in the realization that a spatial interval can conventionally represent a time interval.

In the first experiment, a comparison of normal and retarded readers was made in visual and auditory IMM and $\mathrm{CMM}$, using spatio-temporal patterns in all four conditions.

\section{EXPERIMENT I}

\section{Method}

Subjects. Six retarded readers taking part in remedial training at the Schonell Education Research Centre, Queensland, Australia, were compared with six normal readers matched for age, sex, and IQ. Mean age of the retarded readers was 8 years, 3 months (range of 7-3 to 8-10) and mean IQ was 100 , compared to 8 years, 5 months (range $7-4$ to $8-10$ ) and a mean IQ of 101 , for normal readers. None of the retarded readers had any symptoms of neurological impairment or history of difficult birth, though one child had contracted meningitis in infancy.

Apparatus. Visual signals were presented on two small lights (standard red indicator bezels) mounted about $5 \mathrm{~cm}$ apart to the right and left on a small panel in front of the S. Auditory signals were presented through Akai stereophonic headphones from an A kai stereophonic tape recorder. Frequency-selective filters were used to take information from the tape.

Stimulus Preparation. Both visual and auditory signals were preprogrammed on the tape. A $1,000-\mathrm{Hz}$ tone on one channel was used to operate the right-hand light, while the same frequency tone on the second channel operated signals to the right-hand earphone. The left-hand light and earphone were operated by $5,000-\mathrm{Hz}$ tones on opposite channels. Information was decoded from the tape via the filters which operated relays for the lights and earphones.

Both visual and auditory spatiotemporal patterns were made up of two signals to the right and two to the left in a random order giving six possible combinations of right and left. The visual stimulus was a brief (approximately $100 \mathrm{msec}$ ) flash of light while the auditory stimulus was a prerecorded tone of similar duration. Separate stimulus events (one flash or one tone) occurred $500 \mathrm{msec}$ apart, while each pattern of four consecutive events was separated by $1 \mathrm{sec}$.

Procedure. There were four experimental conditions: visual-visual (VV), auditody-auditory (AA), VA, and AV matching. Conditions were a within-Ss variable with presentation balances in an ABCDDCBA fashion. In each condition a trial consisted of two stimulus patterns, and the $S$ was instructed to say whether the two patterns were "same" or "different." For each S, there were 30 trials per condition in blocks of 10 , the probability of "same" being 0.5 in each block. Ss were given as many practice trials as seemed necessary to make sure that they had understood each task. Knowledge of results was not given.

\section{Results}

A 2 (reading ability) by 4 (modality conditions) ANOVA of correct responses (Table 1), with the first factor as a between-Ss variable and the second as a within-Ss variable, indicated significant main effects for both reading ability $[F(-1,10)=9.59, \mathrm{p}<.01]$ and modalities $[\mathrm{F}(3,30)=17.97, \mathrm{p}<.001]$ and a significant interaction term $[\mathrm{F}(3,30)=21.91, \mathrm{p}<.01]$.

The Newman-Keuls test indicated that retarded readers differed significantly from normal only in AA and AV matching. For normal readers, the IMM conditions did not differ significantly, whereas this difference was significant for the dyslexic group $(\mathrm{p}<.01)$. Similarly, differences between the CMM conditions were significant for dyslexics $(p<.01)$, though not for normal readers.

It seems clear from these results that the retarded reader has difficulty compared to the normal only when he is required initially to process an auditory signal whether this is in IMM or CMM. Rather than indicating failure of integration between vision and audition, the results imply some inability to hold auditory signals in short-term memory (STM). Birch and Belmont (1964) argued against an explanation of AV failures in terms of STM since they found that memory span for auditorily presented digits was not associated with AV matching. However, they did not examine STM for auditory patterns. To check the present interpretation, a second experiment compared visual and auditory STM in both groups of children. Since there is evidence that STM strategies change with age (e.g., Dornbush \& Basow, $1970)$, comparison was also made with a group of adults.

\section{EXPERIMENT II}

\section{Method}

Ss, apparatus, and stimulus presentation were as for the previous experiment. Only VV and AA matching were compared under three conditions. The interval between stimulus patterns was $1 \mathrm{sec}$ as before, a 10 -sec rest interval $(R)$ in which the $S$ heard the first pattern and waited quietly for $10 \mathrm{sec}$ before the second pattern was played, or a 10 -sec task interval $(\mathrm{T})$ in which a counting-backwards task was interpolated between stimulus patterns. The rationale was to explore effects of decay $(R)$ and interference $(T)$ over the 10 -sec interval. Modality conditions were counterbalanced (ABBA), and within each modality intervals were counterbalanced (ABCCBA). Both were within-Ss 
Table 2

Mean Correct Responses (Out of 30) for Visual and Auditory Matching at 1 and 10 Seconds

\begin{tabular}{|c|c|c|c|c|c|}
\hline \multirow{3}{*}{$\begin{array}{l}\text { Reading } \\
\text { Ability }\end{array}$} & \multirow[b]{3}{*}{ Interval } & \multicolumn{4}{|c|}{ Modality Condition } \\
\hline & & \multicolumn{2}{|c|}{ Visual } & \multicolumn{2}{|c|}{ Auditory } \\
\hline & & Mean & $\mathrm{SD}$ & Mean & $\mathrm{SD}$ \\
\hline Normal & $\begin{array}{l}1 \mathrm{Sec} \\
\mathrm{R} \\
\mathrm{T}\end{array}$ & $\begin{array}{l}28.0 \\
23.4 \\
20.0\end{array}$ & $\begin{array}{l}1.10 \\
1.21 \\
1.41\end{array}$ & $\begin{array}{l}27.8 \\
22.8 \\
21.7\end{array}$ & $\begin{array}{l}1.83 \\
1.94 \\
1.03\end{array}$ \\
\hline Retarded & $\begin{array}{l}1 \mathrm{Sec} \\
\mathrm{R} \\
\mathrm{T}\end{array}$ & $\begin{array}{l}28.3 \\
24.5 \\
23.2\end{array}$ & $\begin{array}{l}1.63 \\
1.05 \\
2.93\end{array}$ & $\begin{array}{l}22.5 \\
17.2 \\
14.3\end{array}$ & $\begin{array}{l}3.94 \\
1.60 \\
1.75\end{array}$ \\
\hline
\end{tabular}

variables. In all there were 180 trials (i.e., 30 trials per interval, per modality).

\section{Results}

The present findings support the interpretation of the poorer performance of retarded readers in terms of STM. Mean correct responses are given in Table 2, and it is apparent that merely interpolating a 10 -sec interval between auditory patterns reduces the performance of retarded readers to the chance level.

Since cell variance for adult Ss was generally close to zero, statistical comparison was made between the two groups of children. A 2 (reading ability) by 2 (modalities) by 3 (intervals) ANOVA of correct responses, with the first factor as a between-Ss variable and the second and third as within-Ss variables, showed significant effects of reading ability $[\mathrm{F}(1,10)=56.41$, $\mathrm{p}<.001]$, modalities $[\mathrm{F}(1,10)=22.58, \mathrm{p}<.001]$, and intervals $[F(2,20)=97.57, p<.001]$. Only the Reading Ability by Modalities interaction reached significance, $[F(1,20)=27.08, p<.001]$.

A Newman-Keuls test showed that there was no significant difference between the two groups of children in any of the VV conditions, and that the normal readers were significantly more accurate $(\mathrm{p}<.01)$ in all AA conditions. For the children there was no significant difference between rest and task intervals in either modality condition, i.e., the rest interval was sufficient to produce forgetting. On the other hand, inspection of adult data shows that they were capable of maintaining the same level of performance as at $1 \mathrm{sec}$ over the $\mathrm{R}$ interval in both modalities. STM in adults is disrupted only by the interpolated task. It seems likely, therefore, that adults can use rehearsal strategies which have not been acquired by the children studied here.

\section{DISCUSSION}

It is difficult to interpret the present findings in terms of any failure of intersensory integration since dyslexic and normal readers do not differ in VA matching. There is also evidence that retarded readers may not differ from normal in matching shapes between vision and touch (Hurley, 1968).

One other broadly "integration" explanation of the dyslexic child's relatively poor auditory abilities may be considered. There is evidence that accurate spatial localization of sounds depends upon an integration of eye movements with the position of the sound (Platt \& Warren, 1972; Jones \& Kabanoff, in preparation), and Jones (1972) has argued that spatial perception generally depends upon an integration of sensory input with efferent patterns. The very specificity of the deficit in the present sample of retarded readers tells against the eye-movement hypothesis. Both groups of children must be able to localize sounds with the same accuracy since performance in VA matching is equivalent. The dyslexics can "pick up" sequential auditory information, but lack the ability to retain it in memory. However, it may be in other groups of poor readers that abnormal efferent control of eye-movement patterns is responsible for poor spatial integration in reading (see Zangwill \& Blakemore, 1972).

In the present cases, poor reading ability seems tied in with specifically auditory processing problems; since the dyslexic child shows no inability to understand ordinary spoken language (e.g., the complex instructions necessary to describe the experimental tasks to him), it is likely that such problems are concerned with strategies for coding highly abstract auditory sequences (tones, phonemes, etc.) rather than contextually bound ordinary speech. Bower (1970), among others, has pointed to the need to consider how complex cognitive strategies may operate in seemingly simple STM tasks.

Consequently, there is a need for research into auditory STM strategies in children, both retarded and normal readers, which is not to deny that in some persons deficits in auditory STM are associated with specific neurological lesions (Butters, Barton, \& Brody, 1970). There is simply no one explanation for poor reading ability.

\section{REFERENCES}

Birch, H. G., \& Belmont, L. Auditory-visual integration in normal and retarded readers. American Journal of Orthopsy chiatry, $1964,34,852-861$.

Blank, M., \& Bridger, W. M. Deficiencies in verbal labelling in retarded readers. American Journal of Orthopsychiatry, 1966, 36, 840-847.

Blank, M., Weider, S., \& Bridger, W. H. Verbal deficiencies in abstract thinking in early reading retardation. American Journal of Orthopsychiatry, 1968, 38, 823-833.

Bower, G. H. Organizational factors in memory. Cognitive Psychology, 1970, 1, 18-46.

Bryant, P. E. Comments on the design of developmental studies of cross-modal matching and cross-modal transfer. Cortex, 1968, 4, 127-137.

Butters, N., Barton, M., \& Brody, B. Role of the right parietal lobe in the mediation of cross-modal associations and reversible operations in space. Cortex, 1970, 6, 174-190.

Dornbush, R. L., \& Basow, S. The relationship between auditory and visual short-term memory and reading achievement. Child Development, 1970, 41, 1033-1044. Goodnow, J. J. Matching auditory and visual series: Modality problem or translation problem? Child Development, 1971, 42, 1187-1201.

Hurley, $O$. L. Perceptual integration and reading problems. Exceptional Children, 1968, 35, 207-215.

Jones, B. Facilitation of visual perception by voluntary movement in elementary school-children. Journal of Experimental Child Psychology, 1972, 9, 178-182.

Muehl, S., \& Kremenak, S. Ability to match information within and between auditory and visual sense modalities and subsequent reading achievement. Journal of Educational Psychology, 1966, 57, 230-239.

Platt, B. B., \& Warren, D. M. Auditory localization: The importance of eye movements and textured visual environment. Perception \& Psychophysics, 1972, 12, 245-248.

Rubinstein, L., \& Gruenberg, E. M. Intramodal and cross-modal sensory transfer of visual and auditory temporal patterns. Perception \& Psychophysics, 1971, 9, 385-390.

Zangwill, O. L., \& Blakemore, C. Dyslexia: Reversal of eye-movements during reading. Neuropsychologia, 1972, 10,
$\mathbf{3 7 1 - 3 7 3}$.

(Received for publication October 15, 1973.) 